\title{
Study on Orff's Music Teaching Method
}

\author{
Huili Sun \\ Zhengzhou Institute of Technology, Zhengzhou, Henan, 450000
}

\begin{abstract}
Music is a very creative form of art, is an essential element of aesthetic education, for creativity and innovation has a unique effect to enhance. China's school music education before the reform and opening up is a neglected discipline, until after the reform and opening up with the concept of progress began to be gradually attention. The development of music education in our country, the introduction of Orff music teaching method played a lot of impetus. However, as a kind of foreign music teaching method, the introduction and use in our country is actually the fusion of two different cultural circles. In the process of integration, it has positive effect and inevitably has negative influence. In order to make our music education better development, we need to create suitable for their own, with their own national characteristics of the music teaching method, the introduction of only means to create their own way is fundamental.
\end{abstract}

Keywords: Orff, Music Teaching Method, Teaching Method Reform

\section{Introduction}

Orff's music teaching method is by the German music educator, composer Karl Orff (KarlOrff, 1895-1982) created. Orff, born July 10, 1895 in Munich, Germany, a soldier by family, grandfather and father are officers, mothers are very fond of nature and art. Orff parents of his early education attaches great importance to the cultivation of humanistic spirit, so Orff from the early childhood began to receive art education, but his art education is very relaxed and has a good cultural atmosphere of the environment, to the Olympic The great space to play his superhuman imagination and creativity, not to imitate what is not according to the will of others, but to explore and constantly try all possibilities. Juvenile Orff on classical music, literature, drama is very passionate 
in these areas continue to accumulate self-cultivation, for his future creation has laid a good foundation. In 1924 Orf and Dalcroz students Dorothy • Jun special cooperation in Munich, founded a group gymnastics, music, dance as one of the "military special school", by Orff is responsible for all music courses. Here he began to try to music training in the rhythm as the basic elements, and dance, language, combined to make it into a play the form of musical expression to learn. In 1930 his first music teaching material - "school children's music teaching material" earliest embryonic come out, and in Germany and European countries for performances and teaching demonstrations, caused a sensation.

\section{The reason why Orff's music teaching method is popularized in China}

Dalkerz music teaching method, Kodaly music teaching method, Orff music teaching method is currently in the international reputation of the three music teaching method. But in our country to hear the most is Orff music teaching method, is the other two bad? Obviously it is not, but Orff music teaching ideas and characteristics more in line with our needs. Although they have the same goal: to improve the music of the participants, but the three music teaching methods are produced in different countries by different people in different contexts created, therefore, there are still differences. In his class, the rhythm must be in line with the rhythm of music, the so-called impromptu accompaniment is also right and wrong points, the piano level of teachers is very strict; "free" and "music" Is not entirely in accordance with their own way to do, can be said to prepare for professional music learning in advance; in the selection of teaching materials he does not bind teachers, and encourage teachers to create their own curriculum materials. Kodaly music teaching methods focus on singing, singing and then through the understanding of the score, learning music, the first tune and musical instrument learning; impromptu action is based on the lyrics to design, such as cradle, boating, singing for the action accompaniment, and singing It is unaccompanied; textbooks in the music must be folk music, and is a national musicians that is "the best" "the most real." Orff music teaching method is an inclusive teaching method, can absorb the length of each family, he focused on the students' improvisation, creation, rhythm, according to the students to listen to the music of improvisation express their feelings, without any restrictions And the impact of their own or groups co-authored, can be musical, drama, opera, subject matter is not limited to completely play by the students themselves, teachers do not do too much intervention, this improvisation and creativity can effectively stimulate the creativity of students. Orf's whole music education system to the rhythm-based, he believes that the rhythm is human instinct, is that everyone can learn, almost no difficulty, by continuing to give students a sense of accomplishment and self-confidence, so that students of music learning Interest, affect the lifelong learning of students; the choice of teaching material is Orff according to their own folk songs or nursery rhymes adapted, or their own 
creation according to the curriculum to encourage teachers to create their own national ethnic resources, and Dalcroz Music teaching point of view is the same; Orff advocates for children in the "play" in the process of learning knowledge, his class is the composition of the game, to seize the students like the game psychology.

Orff has always believed that his "original music" education is inherently old tradition. In the Western music concept, often only the music is understood as a sort of sound, that is, "audio ontology" music exist. Chinese people are often in the learning all receive, so a reference to music, often thinking will be in accordance with the Western style, that music is the composition of music tone. Orff did not follow the trend, but the reverse to see the source of mankind, see the more ancient "music ontology" concept. In Chinese traditional music aesthetics and traditional view music education theory, the most important of the philosophical foundation is this "music ontology" concept. "Music" in the "Music" for the "sound" has this record: "Chi micro-kill sound for the sound, but people think;" with irritability, killing gas of the sound and music to give people unconscious irritability and anxiety, "Harmony, slow and easy ... the sound for the people and leisure ..." witty, rhythm and comfortable slow music and sound, people serene and comfortable, what kind of emotional music gives what kind of feelings, which is not It is also Orph "original" concept that he personally involved in music practice, personally feel the emotion, and then through a variety of ways to express their feelings freely.

\section{Application of Orff's Music Teaching Method}

Music is a way people express emotions, although a variety of musical forms have been in the development process slowly from the most primitive form of life, the formation of a standardized music language, but the music itself is a manifestation of vitality, Is the most primitive human emotions. To implement the concept of "original nature", we must first change the traditional teaching mode, which emphasizes theoretical knowledge and performance skills, so that the students are separated from the study by listening to the class, listening to the get out of class, repeating the practice, dull boring traditional theoretical learning process, Encourage students to participate in music in teaching, through the psychological experience and physical experience so that students can tap the feelings expressed by music and thought, so that students enjoy music in learning to bring people to learn while better Of music knowledge. Orff's "original" music philosophy says that "the original music is by no means pure music, it is and action, dance, language closely together; it is a people must participate in their own music, namely: people Not as a listener but as a player. From this we realize that participation in music, in addition to playing outside the body's action is also involved in a form of music, and this form is very applicable to the basic theory of music and music skills The lack of their own music and lack of enthusiasm for learning and difficult pre-school students who. The author guides the student through the simple movement of the body in the music teaching, lets the student 
take the relaxed freedom mentality along with the music melody to enter the music world naturally, feels the music and the body blend, the music and the soul exchange happy feeling.

Music course should be training teachers professional knowledge of music, professional skills courses, it should also be training teachers and other comprehensive art of music literacy ability of the course, for the future can become a comprehensive quality of teaching in the ability to lay a good foundation for educators. Therefore, the music teaching can not be a single theory and skills to teach, but should be interdisciplinary integration, the development of students comprehensive quality of education. However, in the practical work, the author found that our current professional music curriculum set from the teaching content point of view a higher degree of specialization, the contents of the form of a very little integration of other art categories of knowledge, integration with non-art courses less knowledge. This single subject knowledge teaching can be relatively complete in the systematic knowledge of subject knowledge, but the study and utilization of comprehensive knowledge is relatively weak. At present, China's undergraduate professional music teaching content includes basic music theory, vocal music, piano, children's songs and songs and creation, music appreciation, the various parts of the content that has its own independence and a certain degree of systematic. Therefore, when setting up a comprehensive curriculum, it is necessary to systematically analyze the value orientation of the course and combine the actual situation of the undergraduate course to scientifically divide the teaching content into focused unitary courses. Unit curriculum that is relatively independent and mutual integration, both layers of progressive logical contact, but also horizontal parallel, so that the curriculum is to make a curriculum to expand the teaching content and can make a number of courses Teaching content is interrelated, so that students in a limited time and space to master more knowledge of music theory and music skills, to achieve a higher artistic accomplishment of the target.

Innovative education is to cultivate the spirit of innovation and innovation as the basic value orientation of education. At the core of the basic education in the universal, based on the full implementation of the process of quality education, to meet the challenges of the era of knowledge economy, focusing on research and solutions in the field of basic education to cultivate students' innovative consciousness, innovation and innovation. Quality education has been put forward, and the core of quality education lies in the cultivation of creative ability and innovation spirit. Creativity and innovation is precisely the driving force behind the creation of music, therefore, should be taught in the teaching of creative ability and innovative spirit throughout the training. As the American psychologist Abrahan maslon said, "We have to teach our students to be creative people, at least to be able to face the novelty of things, to do improvisation. We need a new kind of human ...they can have the courage and confidence to solve the problem in an improvised way without the need to prepare in advance. "

An appropriate evaluation method should be able to fully reflect the characteristics of music teaching at the same time, both to reflect the students 'learning, but also serve the students' learning; to feedback the students learning 
to increase learning motivation to improve student inquiry Interest, adjust the way of thinking of students to enhance the students' human feelings. Therefore, the evaluation should be targeted, not blindly evaluation; evaluation should be objective, not extreme evaluation; evaluation should be stimulating, not negative evaluation; evaluation should be instructive, not dogmatic evaluation; evaluation should be development. In a good evaluation mechanism, students can learn a better understanding of music, music appreciation, interpretation of music, tap the potential of music, and promote the creation of music, so the true sense of the completion of music learning.

\section{Conclusion}

Through the study on the application of Orff's music teaching method in music teaching, it is believed that through the understanding and refining of Orff's music teaching idea, the reform and innovation of music teaching teaching methods and teaching content, develop students' music Creating the potential to enhance students' love for music and the understanding of music culture for students in the future of music and continuing education and pre-school education to lay a solid foundation.

\section{References}

[1] Liu Jing. Orff music teaching method of the localization process of China [J]. Music, 2014 (01)

[2] Dong Qian. "Music education return to children's lives" - On Orff music education [J]. Scientific Management (Technology Management), 2014 (01)

[3] Zhu Haiping. Orff rhythm training in junior high school music teaching [J]. Middle School Teaching Reference, 2012 (36)

[4] Yang Li, Chen Xuefang, Ma Zhicheng. Orff music activities and traditional music activities [J]. Vocational and Technical, 2002 (11)

[5] Wang Lixin. Orff music localization of the constraints of teaching methods. [J]. Journal of Northeast Normal University (Philosophy and Social Sciences), $2012(02)$

[6] Cui Xu. Orff teaching method in the importance of music teaching [J]. Science and Technology Information, 2012 (08) 